\title{
Los derechos digitales en Europa tras la entrada en vigor del Reglamento de Protección de Datos Personales: un antes y un después para el derecho al olvido digital
}

\author{
Digital rights in Europe after the Personal Data Protection \\ Regulation: a before and after for the right to be forgotten
}

\author{
Ángela Moreno Bobadilla \\ Universidad Andrés Bello \\ angela.moreno@unab.cl1
}

\begin{abstract}
Resumen: Europa se ha convertido en el continente que ha desarrollado de forma más prolija el derecho al olvido digital, no solamente dentro de la Unión Europea, sino también en el ámbito de los ordenamientos jurídicos nacionales de sus Estados miembro. El presente artículo comienza haciendo un repaso de las primeras sentencias que se dictaron en la materia, y que son previas a la creación de internet, para posteriormente analizar el punto de inflexión que se produjo en el año 2014 con el Caso Costeja, y que influyó directamente en la nueva legislación que se ha dictado en la materia tanto en el Parlamento de Bruselas, como en los diferentes parlamentos nacionales europeos. Todo ello con el objetivo de poder demostrar la
\end{abstract}

1 Proyecto Fondecyt Iniciación 11180172 "Aspectos fundamentales para la configuración y el desarrollo del derecho al olvido digital en Chile".

Doctora por la Universidad Complutense de Madrid. Graduada en Derecho por la UNED y Licenciada en Periodismo por la Universidad Complutense de Madrid.

Profesora de Derecho Constitucional de la Facultad de Derecho de la Universidad Andrés Bello.

Artículo recibido el 28.09.2019 y aceptado para publicación el 27.05.2020. 
complejidad de este derecho poliédrico tan importante para los ciudadanos en la actual sociedad digital.

Palabras clave: Derecho al olvido, derechos digitales, RGDP, Unión Europea.

Abstract: Europe has become the continent that has developed the right to digital oblivion more neatly, not only within the European Union, but also within the scope of the national legal systems of its member state. This article begins by reviewing the first sentences that were issued on the subject, and that are prior to the creation of the internet, to later analyze the turning point that occurred in 2014 with the Costeja Case, and which directly influenced the new legislation that has been issued on the subject both in the Brussels Parliament, and in the different European national parliaments. All this with the aim of being able to demonstrate the complexity of this polyhedral right so important for citizens in today's digital society.

Keywords: The right to be forgotten, digital rights, GDPR, European Union.

\section{Introducción}

Los datos personales son la principal materia prima del siglo XXI. Pero lo valioso no es el dato en sí mismo, sino la información que aporta². Las empresas que operan en internet tienen miles de datos de todos los ciudadanos que navegan por la Web 2.0, con los que construyen perfiles psicológicos para predecir no solamente los patrones de consumo, sino cuestiones tan importantes como sus intenciones de voto, influenciando y prediciendo el comportamiento de la opinión pública, tal como evidenció el escándalo protagonizado por la ya desaparecida empresa de Cambridge Analytica.

En este contexto, en el que internet se ha integrado en la vida cotidiana de los ciudadanos, la protección de la privacidad y de los datos personales se ha convertido en una necesidad imperiosa. Es importante que haya una garantía efectiva de los derechos digitales de los ciudadanos. Garantía que impone a su vez unas

2 Adsura (2018), p. 167: "Un nombre, un apellido, una ciudad de nacimiento, una edad, una talla, un peso, un color de ojos o de pelo, etc., son datos que pueden compartir muchas personas y que, por tanto, no son propiedad exclusiva de ninguna. No se proteger los datos en sí mismos, sino que aportan información sobre el honor o la intimidad de alguien, que son los bienes jurídicos (finalmente) que realmente se protegen". 
obligaciones tanto para las empresas privadas, como para los poderes públicos 3 . En palabras de Paloma Herrera "en la medida en que se implementen políticas públicas tendientes a concientizar a la ciudadanía en materia y protección de datos, los usuarios serán más cautelosos con el contenido que compartan, evitando además la trasgresión a la privacidad de los demás"4.

Precisamente el derecho al olvido digital se enmarca dentro de ese conjunto de derechos digitales que es necesario proteger, por las consecuencias de la perpetuidad de la información que circula por el universo virtual5. Tal como ha dicho la Commission Nationales de l'Informatique et des Libertés de Francia: "Es inaceptable y peligroso que la información publicada en línea de una persona permanezca fija e intangible, mientras que la naturaleza humana implica, precisamente, que las personas cambian, se contradicen y, en definitiva, evolucionan por naturaleza. Esto se aplica a todo, pues hay que proteger la libertad de expresión y la libertad de pensamiento, pero también el derecho a cambiar de opinión, religión, opinión política, la posibilidad de cometer errores de juventud o cambiar de vida"6.

Por ello, el objetivo de la investigación es determinar la significación del derecho al olvido dentro del ámbito de la Unión Europea, debido a que es en el Viejo Continente donde se ha producido un mayor desarrollo de esta cuestión, y que está sirviendo de modelo en otros ordenamientos jurídicos, como por ejemplo en Chile, donde se está discutiendo una nueva ley en materia de privacidad ${ }^{7}$ y que va

3 Rallo (2019), p. 30: "Garantizar un acceso universal a Internet sin discriminaciones técnicas o socioeconómicas no solo obliga a una acción de los poderes públicos sino que impone límites a las actividades comerciales de los operadores y servicios de Internet".

4 Herrera (2016), p. 101.

5 Moreno (2019), p. 260: "Hasta la creación de la Web 2.0, la memoria tradicional imperaba sobre la memoria digital, abocando al olvido de ciertos datos, de ciertas informaciones, que el mero transcurso del tiempo convertía en irrelevantes".

Reusser (2018), p. 81: “... todo nuestro entramado de relaciones sociales está basado en el hecho de que, como personas y con nuestras naturales limitaciones, en un relativo corto plazo nuestra memoria cederá, olvidaremos algunas situaciones de desagradable o doloroso recuerdo, las experiencias felices también se tornarán vagas $y$, consecuentemente, en algún momento dejaremos de reprocharnos mutuamente las acciones $\mathrm{y}$ faltas que nos pudieren haber ofendido. Como correlación a esta realidad, el sistema jurídico funciona con idéntica lógica: las deudas prescriben, las ofertas caducan, se dictan amnistías, los plazos precluyen, etc.; es decir, después de cierto tiempo nos olvidamos de los temas, incluso por mandato legal".

6 3oe Rapporte d' Activité 2009 de la Commission Nationales de l'Informatique et des Libertés, p. 26.

7 En Chile actualmente está vigente la Ley 19.628 sobre Protección de la Vida Privada de 1999, donde no se hace ninguna referencia al tema del derecho al olvido digital, ya que se trata de una ley muy anticuada y desfasada con la actual sociedad digital.

Son numerosas las iniciativas que ha habido en los últimos años y que buscan la protección del derecho al olvido digital (Boletín № 8208-07, Boletín № 9388-07 y Boletín 10608-07), pero el texto que puede llegar a 
a contemplar la protección de este derecho, así como la creación de un organismo autónomo de carácter administrativo que se encargue de su protección.

El artículo va a partir analizando el ámbito jurídico protegible del derecho al olvido, ya que se trata no solamente de un derecho relacionado con el derecho de supresión, sino que se va a comprobar que en realidad se trata de un derecho mucho más complejo, debido a la multiplicidad de situaciones a las que está tratando de dar respuesta. Para ello se hace un repaso de los principales hitos jurisprudenciales que sembraron los orígenes del olvido, previos a la era digital, y el punto de inflexión que marcó en su evolución la sentencia del Caso Costeja.

A continuación, la investigación se centra en el ámbito de la Unión Europea, para estudiar en primer lugar el significado e impacto que ha tenido en este sentido el nuevo Reglamento de Protección de Datos Personales, que se encuentra en vigor desde el mes de mayo de 2018. Posteriormente analiza la incorporación de este instrumento jurídico en algunos de los Estados miembro, con la especial incidencia del caso español, país que ya ha procedido a actualizar la legislación de esta materia para dar pleno cumplimiento a las exigencias dadas por la Unión Europea.

\section{Un repaso de la jurisprudencia relativa a los orígenes y evolución del derecho al olvido}

El derecho al olvido digital es objeto de gran expectación como consecuencia de la relevancia y necesidad de su regulación en la sociedad actual. Pero para poder comprender el punto en el que se encuentra, es necesario, en primer lugar, hacer un repaso jurisprudencial de las primeras sentencias que, mucho antes de la creación de internet, ya mencionan el derecho que los ciudadanos tienen a ser perdonados y a una segunda oportunidad.

Además, es importante analizar la sentencia del Caso Costeja que, en el año 2014, marcó un punto de inflexión y ayudó a la codificación de este derecho, que no solamente deriva de la protección de datos, sino también de la intimidad ${ }^{8}$. Incluso hay una parte de la doctrina que aboga por que su fundamento está basado

dar respuesta a estos interrogantes finalmente podría ser el proyecto de ley ingresado el 15 de marzo de 2017 (Boletín No 11114-07).

8 Álvarez (2015), p. 27: "El derecho al olvido encuentra sus raíces en el derecho a la intimidad (the right to privacy en su denominación en inglés) y en el derecho a la protección de datos personales, pudiendo considerarse que el derecho al olvido deriva de ellos". 
en el libre desarrollo de la personalidad ${ }^{9}$, y por lo tanto, no se puede relacionar de forma tan estricta solamente con estos dos derechos de la personalidad.

Esta postura, aunque un tanto minoritaria, es muy acertada, ya que permite que un derecho tan poliédrico como el derecho al olvido, no se limite a ser un derecho de supresión que solamente se destine a proteger información que contenga datos personales o datos íntimos ${ }^{10}$, sino que pueda ir más allá y prever las nuevas situaciones de vulneración que los avances tecnológicos van a seguir poniendo sobre la mesa, y que tal como se va a poder evidenciar a continuación, van cambiando las necesidades de reconocimiento y protección de los derechos fundamentales de los ciudadanos.

\subsection{Los orígenes del derecho al olvido}

Los orígenes del derecho al olvido son previos a la era digital. Concretamente se remontan a finales del siglo XIX.

Desde la publicación del artículo de Warren y Brandeis, y durante las dos primeras décadas del siglo XX, en Estados Unidos se empezó a forjar una postura favorable hacia la protección de este derecho, que dio paso a que en los años 30 ya se puedan encontrar los primeros casos en los que los ciudadanos no solamente reclaman por su privacidad, sino también por el olvido.

Fue precisamente este país uno de los primeros en resolver un caso de derecho al olvido anterior a la era digital: el Caso Melvin $v$. Reid en $1931^{11}$, en el que la

9 Véase en este sentido: Anguita (2016), Simón (2015) y MuÑoz (2015).

Para Pere Simón el derecho al olvido encuentra su fundamento en la dignidad humana, con objeto de que cada persona pueda determinar de forma libre su vida, tanto presente como futura. Tal como el autor manifiesta: "El derecho al olvido digital, como manifestación de la dignidad humana y el libre desarrollo de la personalidad, puede ser interpretado en el sentido de tutelar a los ciudadanos frente a la difusión de todas las informaciones pasadas que les puedan afectar en el futuro, con indiferencia de si afectan o no a los derechos de la vida privada, siempre que las informaciones no estén amparadas en el marco de las libertades informativas" SIMÓN (2015), p. 183.

10 En palabras de Nogueira (2002), p. 147: "La intimidad es el ámbito reservado del individuo que no desea ser develado al conocimiento y acción de los demás, el cual aparece como necesario para mantener un mínimo de la calidad de vida humana. El derecho a la intimidad es la facultad de la persona para evitar las injerencias de terceros en el ámbito de su privacidad, salvo la autorización de tal develamiento de la intimidad por el propio afectado. La intimidad de la persona es una zona intrínsecamente lícita, que merece respeto y protección a nivel constitucional".

11 Los llamativos hechos comenzaron en 1918, cuando Gabrielle Darley, de profesión prostituta, comenzó una relación amorosa con el deportista Leonard Tropp. Tras un tiempo de noviazgo, ella le dio dinero para que le comprase un anillo de bodas, sin saber que, en realidad, él planeaba casarse con otra mujer a la que le regaló la mencionada sortija que había comprado con el dinero de Gabrielle. 
Corte de Apelaciones de California consideró que los hechos habían producido una violación en la privacidad de la señora Darley, y que las personas deben tener derecho a olvidar y a ser perdonadas.

Este se convirtió en uno de los casos más emblemáticos en esta materia, ya que se puede considerar que es un reconocimiento jurisprudencial del derecho al olvido, del derecho a tener una segunda oportunidad, donde se pueden olvidar los hechos del pasado cuando ya no tienen relevancia para la conformación de la opinión pública del presente, y guardando el delicado equilibrio que es necesario mantener entre los derechos de la personalidad y el derecho a la información.

Esta tendencia fue revertida en el caso Time Inc. $v$. Hill de 1967, en el que se comenzó a hablar de las figuras públicas involuntarias ${ }^{12}$.

La Corte Suprema entendió que no había violación en la privacidad de la familia Hill, sentando el criterio jurisprudencial de la figura pública involuntaria por su implicación en hechos noticiosos, y provocando que, a partir de este momento, en Estados Unidos, no haya olvido para ninguna persona sin importar la situación.

El Tribunal Supremo añadió un nuevo argumento constitucional sobre la prevalencia de la libertad de expresión respecto del derecho a la intimidad, al expresar que la Primera Enmienda ya no estaba destinada a proteger únicamente la expresión política o el comentario de los asuntos públicos, sino también la información noticiosa ${ }^{13}$.

Esta jurisprudencia ha sido corroborada en casos posteriores como el de Briscoe v. Reader's Digest Assoc. de 1971, en los que los tribunales consideraron que un

A raíz de los hechos, Gabrielle le disparó en la calle y él murió. En el juicio, ella fue declarada inocente, debido a que convenció al jurado de que el revólver se había disparado accidentalmente.

Años más tarde, Adela Rogers, hija de Leonard, escribió una historia, The Red Kimono, contando todos los hechos ocurridos y dando los nombres reales de los protagonistas. Esta fue llevada al cine en 1927.

Como consecuencia, Gabrielle demandó a Adela por invasión de su derecho a la privacidad, ya que ella había rehecho su vida y clamaba por una segunda oportunidad.

12 La familia Hill fue secuestrada en su casa en 1952 por 3 criminales convictos. A raíz de estos hechos, el matrimonio y sus cinco hijos se mudaron de Pennsylvania con objeto de poder volver a tener una vida de anonimato.

La revista Time publicó un reportaje sobre el caso, debido a que también se había creado una obra de teatro en Broadway con el nombre "The Desperate Hours", adaptación del libro escrito por Joseph Haye.

13 Covarrubias (2013), p. 27o. "Con este avance en perjuicio de la intimidad, el Tribunal otorga escudo constitucional a la prensa para reportear la vida de personas privadas involucradas involuntariamente en hechos noticiosos". 
personaje público no se vuelve a convertir en persona privada por el mero transcurso del paso del tiempo.

En este caso, el Máximo Tribunal estadounidense revirtió una sentencia de la Corte de Apelaciones de California en la que había dado la razón al señor Briscoe que demandó a la revista Reader's Digest por publicar un reportaje sobre su pasado criminal. Pero la Corte Suprema confirmó el criterio de que una persona que se ha convertido en pública, nunca más vuelve a ser privada.

Europa también participó en los orígenes del derecho al olvido digital, ya que entre los años 60 y 80 los tribunales franceses dictaron jurisprudencia relativa a esta materia, posicionándose el país como un firme defensor de las segundas oportunidades.

Un ejemplo es la sentencia del Tribunal de Gran Instancia de Sena, del 4 de octubre de 1965, muy pionera al reconocer el derecho de los ciudadanos a tener una segunda oportunidad ${ }^{14}$. A pesar de que finalmente el órgano jurisdiccional francés rechazó la demanda, ya que la actora había publicitado su relación con el señor Landru, se comienza a hablar del droit a l'oublie, sembrándose los orígenes europeos del derecho al olvido previo a la era digital.

El mismo criterio se utilizó frente a la publicación de la autobiografía del famoso delincuente Mesrine, cuya expareja reclamaba que el libro perjudicaba su reinserción social. Este caso se puede ver en la sentencia del Tribunal de Gran Instancia de París, del 6 de diciembre de 1979.

Otro ejemplo es el caso Mme. M. c. Filipacchi et Cogedipresse de 1983, que también defendió que las personas privadas que se hayan visto involucradas en acontecimientos públicos, pueden reivindicar el derecho al olvido cuando dicha información ya no tenga interés para la conformación de la opinión pública. Esto debido a que el recuerdo de esos acontecimientos, cuando no esté fundado en necesidades históricas o si su naturaleza es tal que puede herir su sensibilidad, no se puede considerar legítimo.

Todos estos, son tan solo algunos de los ejemplos de la importante y sólida jurisprudencia que se sentó en Francia relativa al olvido en el caso de informaciones protagonizadas por personas privadas que se han convertido en irrelevantes debido al paso del tiempo, por lo que sus protagonistas tienen derecho a volver a

14 Resolvió una demanda de una de las amantes del famoso asesino en serie Henri Landru, porque su relación sentimental fue representada en una película muchos años después de que el noviazgo hubiese ya finalizado. 
comenzar. Además, el país galo dictó, de forma muy prematura, la Ley 78-17, de 6 de enero de 1978, que regulaba la libertad del tratamiento de informaciones personales, disponiendo el principio del derecho al olvido digital.

En definitiva, esta necesidad de perdón y rendición, denominada derecho al olvido, es anterior a la revolución tecnológica. Los tribunales, principalmente en Estados Unidos y en Francia, contribuyeron a conformar los orígenes del emergente derecho tan debatido en la actualidad. Y siempre con un pilar común: personas privadas, que debido a diversas circunstancias ajenas a su voluntad, se han convertido en públicas. Como consecuencia solicitan que las mencionadas informaciones desaparezcan del radar de la opinión pública, bajo el argumento de que el transcurso del tiempo las ha convertido en irrelevantes.

\subsection{Un punto de inflexión: el Caso Costeja}

A pesar de este punto de encuentro entre ambos continentes, a raíz del boom digital se comienzan a apreciar grandes diferencias, que hacen parecer que Estados Unidos y Europa tienen posturas antagónicas e irreconciliables.

Debido a que desde la creación de la Web 2.0 cualquier noticia del pasado es accesible tan solo introduciendo en un buscador el nombre de la persona sobre la que se desea obtener cualquier tipo de información, con independencia de si esta sigue o no teniendo interés público, los diferentes ordenamientos jurídicos se han manifestado al respecto.

En el caso de los países de la Europa Continental, se considera que el interés público desaparece con el paso del tiempo, por lo que la información no debiese estar siempre accesible ${ }^{15}$. Y esta es precisamente una de las dos grandes diferencias entre el sistema de la Unión Europea y Estados Unidos, ya que en este último país se considera que el interés público no desaparece con el paso del tiempo ${ }^{16}$. En palabras de Pere Simón "el interés público no es eterno, es decir, que la relevancia pública no es necesariamente permanente en el tiempo porque precisamente el paso del mismo conduce a su desaparición. El interés público, en determinados

15 Simón (2015), p. 61: “Una de las principales características del ciberespacio es la preservación del pasado y la perennidad de la información, que se produce por defecto por la propia naturaleza y arquitectura red. Todo aquellos que los usuarios comparten en Internet queda grabado o registrado por defecto, lo que puede conllevar efectos perversos si tenemos en cuenta que la red registra grandes cantidades de información de las personas".

16 Simón (2015), p. 113: "La jurisprudencia norteamericana reconoce a la ciudadanía un derecho a recordar y decidir teniendo en cuenta los hechos pasados". 
casos, es caduco o transitorio, cosa que contrasta con la perpetuidad de la información en la red"17.

Además, en el año 2014 con la sentencia del Caso Costeja ${ }^{18}$, dictada por el TJUE $^{19}$ (comúnmente conocido como Tribunal de Luxemburgo), se produce un punto de inflexión que no hace sino consolidar el derecho al olvido europeo, y fomentar su oposición dentro de uno de los principales exponentes del common law. Mientras que en el Viejo Continente se empieza a considerar que los motores de búsqueda, dígase Google, Yahoo o Bing entre otros, sí que son responsables por el tratamiento de datos, el país donde radica Silicon Valley se alza contra esta postura $^{20}$.

El litigio se basaba en saber si Google estaba obligada a borrar de internet todos los datos personales de la noticia, y que se recuperaban a través del motor de búsqueda. Dicha información pertenecía al pasado de la vida privada del ciudadano.

Debido a ello, se configura un derecho al olvido en el que la única cuestión es que la información se desindexa del buscador, es decir, que no está accesible cuando se google el nombre de esa persona, pero que sigue estando en la fuente

17 Simón (2015), p. 199.

18 El señor Costeja, reputado empresario catalán, había sido protagonista de una noticia en el periódico española de La Vanguardia porque figuraba en un anuncio de una subasta de inmuebles relacionada con un embargo de deudas a la Seguridad Social. Estos hechos habían tenido lugar mientras desarrollaba sus actividades empresariales, en las que dejó de pagar las cuotas a la Seguridad Social, que tuvieron como consecuencia el mencionado embargo.

El hecho de que cada vez que se introducía su nombre y apellidos en un buscador apareciese la mencionada información, le impedían que tuviera una segunda oportunidad. Además argumentaba que la noticia ya no tenía interés público en la actualidad, y solicitaba que esta no fuese accesible cuando su nombre se escribía en un buscador.

19 Tribunal de Justicia de la Unión Europea.

20 Moreno (2019), p. 269: "Pero el problema en este punto se presenta en que en Estados Unidos, a diferencia de en Europa, los motores de búsqueda no son responsables de la información que almacenan, y en consecuencia las peticiones solamente pueden estar dirigidas a la eliminación de la información de la fuente de origen. Y en este caso, sí que se puede producir una afectación de la libertad de prensa”. 
original, por ejemplo en la hemeroteca digital del diario en el que apareció la noticia $^{21}$, no vulnerándose el derecho a la información ${ }^{22}$.

Se pueden suprimir datos personales cuando estos ya no son necesarios, cuando el interesado haya retirado el consentimiento, cuando los datos hayan sido tratados ilícitamente, cuando deban suprimirse para el cumplimiento de una obligación legal o cuando se hayan obtenido en relación con la oferta de servicios de la sociedad de la información de un niño.

Sus límites dicen relación cuando el tratamiento de los datos sea necesario, para ejercer el derecho a la libertad de expresión e información, para el cumplimiento de una obligación legal, por razones de interés público o con fines de archivo en interés público, fines de investigación científica o histórica o fines estadísticos, así como para la formulación, ejercicio y defensa de reclamaciones.

En definitiva, el Tribunal determinó que los ciudadanos pueden solicitar la eliminación de datos personales contenidos en la Red, cuando su tratamiento sea ilegítimo, o sea, que no sea adecuado, pertinente o excesivo en relación con los fines y el tiempo transcurrido. Por lo tanto, se pronunció a favor del ciudadano, exigiendo la desindexación de la información tanto de Google Inc como de Google Spain ${ }^{23}$.

No obstante, la información sigue accesible en el universo virtual cuando esta se busca a través de parámetros diferentes del nombre del señor Costeja, no implicando que la información quede suprimida de la fuente original. La única con-

21 MuÑoz (2015), pp. 216- 217: "En primer término, dejemos establecido que entendemos el derecho al olvido como aquella facultad que surge de la reunión de dos presupuestos: i) el acceso de forma limitada en el tiempo a información digital que contenga datos personales; y, ii) el derecho del titular de los datos a exigir la eliminación, cancelación, desindexación o, en su caso, bloqueo de dicha información (cuando, por ejemplo, la vigencia de los datos sea dudosa), al menos de los motores de búsqueda, cuando la publicidad de dichos datos ya no se encuentra justificada o se hayan cumplido los fines para los cuales estos fueron publicados. Todo ello, teniendo como límite el respeto de garantías fundamentales, tales como la libertad expresión y de información, y la libertad de prensa".

22 En Chile, desde el año 2015 hasta la actualidad, hay numerosas sentencias de la Corte Suprema y de diferentes Cortes de Apelaciones que hablan del tema del derecho al olvido. El problema que existe, es que al no haber una legislación actualizada al respecto, en algunos casos los fallos son contradictorios, y no queda claro la responsabilidad de los motores de búsqueda.

Véase en este punto las siguientes sentencias: Corte Suprema, causa Rol № 36753-2015, causa Rol № $12873-$ 2015, causa Rol No 9973-2015, causa Rol No 7148- 2015, causa Rol No 9301-2010; Corte de Apelaciones de Punta Arenas, causa Rol No 708-2016, causa Rol oo 682-2015, causa Rol № 75-2012; Corte de Apelaciones de Santiago, causa Rol No 101605-2015, causa Rol No 1495-2010; Corte de Apelaciones de Iquique, causa Rol No 231-2015).

23 RALLO (2014). El ex director de la AEPD hace un exhaustivo análisis de esta Sentencia. 
secuencia práctica, es que el dato (o información no deseada) quede desvinculado del nombre concreto cuando se realiza una búsqueda. Esto para guardar un equilibrio entre el derecho al olvido y el derecho a la información, tal como manifiesta el Tribunal de Luxemburgo en la sentencia aludida.

Es importante explicar que lo que realmente provocó esta cuestión prejudicial ante el TJUE, fue la labor que la $\mathrm{AEPD}^{24}$ llevaba desempeñando desde hacía varios años, dictando centenares de procedimientos contra el gigante norteamericano en el que se le instaba a eliminar de sus resultados de búsquedas los datos de los ciudadanos que reclamaban ante el organismo administrativo, y cuyas resoluciones eran aceptadas.

Y es que, en el 2009 la $\mathrm{AEPD}^{25}$ consideró por primera vez que Google era responsable del tratamiento de los datos, en la Resolución de 26 de enero del mencionado año : "La libertad de información no impone que los datos personales del reclamante figuren en los índices que utiliza Google para facilitar al usuario el acceso a determinadas páginas, ni tampoco preceptúa que figura las páginas que Google conserva temporalmente en memoria "caché", al no ser la de buscar contenidos en internet una actividad amparada por la libertad de información".

Además, no en todos los casos las peticiones son atendidas, sino solamente cuando hay un motivo legítimo y fundado; ese motivo se refiere a su concreta situación personal; el motivo alegado justifica el derecho de oposición solicitado; y en el caso de información de relevancia pública, que los datos sean inexactos o hayan quedado obsoletos.

Previo a recurrir a las diferentes agencias de protección de datos, ya se puede solicitar directamente a los buscadores que se desindexe cierta información ${ }^{26}$. En

\footnotetext{
24 Agencia Española de Protección de Datos.

25 A diferencia de Europa y del resto de países de Sudamérica, en Chile todavía no se cuenta con una Agencia de Protección de Datos que se encargue de velar por los derechos digitales de los ciudadanos.

El proyecto de ley, al que se ha hecho mención anteriormente, contempla la creación de este organismo administrativo, pero todavía no hay una claridad de si va a ser independiente del Consejo para la Transparencia o no.

26 OrZA (2018), p. 153-154: "Concretamente a fecha de 29 de mayo de 2014 las solicitudes ascienden a 713.255 en las que se pedía la retirada u ocultación de 2.00o.321 páginas web. De este total de solicitudes ha aceptado el 43,1 por ciento y ha rechazado el 56,9 por ciento. Por lo que se refiere concretamente a España, ha recibido 57.418 solicitudes que ha llevado a analizar a 170.809 páginas. De ellas ha admitido solo el 38 por ciento, mientras que ha rechazado el 62 por ciento. El país europeo que ha presentado un mayor número de solicitudes es Francis, con un total de 227.318 solicitudes y 411.918 páginas analizadas. Hasta este momento, ha aceptado el 48,7 por ciento de las solicitudes y ha rechazado al restante 51,3 por ciento".
} 
caso de que esta respuesta no sastisfaga al ciudadano, es el momento en el que acuden a los organismos administrativos.

En estos momentos, la nueva polémica surgida en torno al derecho al olvido digital en la Unión Europea es la relacionada con la cuestión prejudicial planteada por la Commission nationale de l'informatique et des libertés de Francia respecto de si en una solicitud que se acoja favorable, el resultado debe desindexarse no solamente de los dominios que Google tiene en Europa, sino a nivel mundial.

Esto se debe a que en cada país Google tiene un dominio diferente, y en el caso del ".com" redirige la búsqueda de forma automática al nombre de dominio que corresponde al país desde el que considera que dicha búsqueda se ha efectuado, gracias a la identificación de la dirección IP del internauta. Sin embargo, con independencia de su localización, los usuarios pueden efectuar sus búsquedas en los demás nombres de dominio del motor de búsqueda.

Esta cuestión, que no quedó resuelta en la anterior sentencia, ha suscitado una gran polémica que todavía está pendiente de resolverse por el Tribunal de Luxemburgo. En palabras de Ramón Orza "tanto Google como otras empresas, sobre todo radicadas en los Estados Unidos, se resisten a que la regulación europea pueda ser exportada a todos los países y se niegan a aplicar estas limitaciones fuera del ámbito de la Unión Europea" ${ }^{27}$.

No obstante, las conclusiones presentadas por el Abogado General Maciej Szpunar defienden que los motores de búsqueda están obligados solamente a suprimir los enlaces dentro de la Unión Europea. En la parte final de su escrito explica que "en ese contexto, ese gestor está obligado a adoptar todas las medidas a su alcance para garantizar una retirada de enlaces eficaz y completa. Ello incluye, en particular, la técnica del "bloqueo geográfico" desde una dirección IP supuestamente localizada en uno de los Estados miembros".

Todavía habrá que esperar a que el órgano jurisdiccional de la Unión Europea se pronuncie a este respecto.

\section{Olvidar en la Unión Europea: un antes y un después del RGDP}

Tras los hechos ocurridos en 2014, se vio que la Directiva 95/46 se había quedado obsoleta, y por lo tanto, era necesario actualizar la legislación referente a esta materia. En este contexto, el 25 de mayo del 2018 entró en vigor el Reglamento (UE)

27 Orza (2018), p. 150. 
2016/679 del Parlamento Europeo y del Consejo, de 27 de abril de 2016, relativo a la protección de las personas físicas en lo que respecta al tratamiento de datos personales y a la libre circulación de estos, conocido por sus siglas RGDP.

Es importante señalar que este instrumento jurídico se aplica a los responsables del tratamiento de las redes sociales, pero no a las actividades que sean exclusivamente domésticas o personales ${ }^{28}$, es decir, para peticiones que los usuarios hagan en materia de pedir la eliminación de ciertos datos que aparezcan en las redes sociales. Esta cuestión se regula en las legislaciones nacionales de cada uno de los Estados miembro.

En el nuevo Reglamento el derecho al olvido ${ }^{29}$ ha quedado regulado expresamente tanto como un derecho del interesado y como una obligación del responsable del tratamiento de los datos ${ }^{30}$. Y es que, tal como manifiesta en el considerando 39 "para garantizar que los datos personales no se conservan más tiempo del necesario, el responsable del tratamiento ha de establecer plazos para su supresión o revisión periódica. Deben tomarse todas las medidas razonables para garantizar que se rectifiquen o supriman los datos personales que sean inexactos".

El RGDP utiliza el término de derecho al olvido como sinónimo del derecho de supresión, a pesar de que, tal como ha quedado ya señalado, el derecho al olvido, en algunos casos va más allá del derecho de supresión ${ }^{31}$. El considerando 66 del RGDP manifiesta que "a fin de reforzar el "derecho al olvido" en el entorno en línea, el derecho de supresión debe ampliarse de tal forma que el responsable del tratamiento que haya hecho públicos datos personales esté obligado a indicar

28 Art. 2.2. c) RGDP: “El presente Reglamento no se aplica al tratamiento de datos personales efectuado por una persona física en el ejercicio de actividades exclusivamente personales o domésticas".

29 APARICIO (2018), p. 393: "El derecho que regula el RGDP se centra en la protección al individuo respecto de la información publicada en Internet. El derecho al olvido es el derecho que permite a las personas eliminar las referencias a algunos hechos de su vida que aparecen reflejados en Internet y que, con independencia de su origen y de si son verdaderos o no, podrían afectar a su desarrollo ulterior como personas".

3 O Moreno y Serrano (2017), p. 44: "El nuevo Reglamento surge como respuesta a la descoordinación que existe en Europa a la hora de que cada Estado aplique las normas europeas. Surge con vocación de unificar criterios, y además trata de dar respuesta a la pregunta de qué ocurre cuando el responsable del tratamiento está fuera de las fronteras, porque hay un claro interés legislativo por defender los derechos de los ciudadanos europeos en relación a la protección de sus datos".

31 Considerando 65 RGDP: "Los interesados deben tener (...) un "derecho al olvido" si la retención de tales datos infringe el presente Reglamento o el Derecho de la Unión o de los Estados miembros aplicable al responsable del tratamiento (...). Este derecho es pertinente en particular si el interesado dio su consentimiento siendo niño y no es plenamente consciente de los riesgos que implica el tratamiento, y más tarde quiere suprimir tales datos personales, especialmente en internet. El interesado debe poder ejercer este derecho, aunque ya no sea un niño". 
a los responsables del tratamiento que estén tratando tales datos personales que supriman todo enlace a ellos, o las copias o réplicas de tales datos. $\mathrm{Al}$ proceder así, dicho responsable debe tomar medidas razonables, teniendo en cuenta la tecnología y los medios a su disposición, incluidas las medidas técnicas, para informar de la solicitud del interesado a los responsables que estén tratando los datos personales".

Estos considerandos son desarrollados en el artículo 17 del RGDP, que no hace sino hablar de que el interesado tendrá derecho a la supresión de datos cuando concurra alguna de las siguientes circunstancias, numeradas en el inciso segundo del mencionado artículo:

a) Que los datos ya no sean necesarios en relación con los fines para los que fueron recogidos o tratados.

b) Que el interesado retire el consentimiento que dio para el tratamiento de sus datos.

c) Que el interesado se oponga al tratamiento por motivos particulares, y no prevalezcan otros motivos legítimos para el tratamiento, o el interesado se oponga al tratamiento de datos cuy objeto sea la mercadotecnia.

d) Que los datos personales hayan sido tratados lícitamente.

e) Que los datos personales deban suprimirse para el cumplimiento de una obligación legal establecida en el Derecho de la Unión o de los Estados miembros que se aplique al responsable del tratamiento.

f) Que los datos personales se refieran a niños menores de 16 años y se hayan obtenido en relación con la oferta de servicios de la sociedad de la información.

Por otra parte, el derecho no podrá ejercerse cuando el tratamiento sea necesario (art. 17.3 RGDP):

a) Para ejercer el derecho a la información o a la libertad de expresión.

b) Para el cumplimiento de una obligación legal impuesta por el Derecho de la Unión.

c) Por razones de interés público en el ámbito de la salud pública.

d) Por razones de archivo en interés público, interés científico, histórico o estadístico, siempre que el ejercicio del derecho al olvido hiciese imposible o dificultara en exceso la consecución de estos fines. Caso contrario deberá procederse al borrado. 
e) Para la formulación, el ejercicio y la defensa de reclamaciones.

En palabras de Artemi Rallo “... la interpretación conjunta del art. 17 RGDP y de los Considerandos 65 y 66 nos permite concluir que el art. 17 RGDP únicamente consagra el tradicional derecho de supresión mientras que del derecho al olvido únicamente se recoge una manifestación básica (informar a terceros sobre la petición de supresión y cancelar réplicas online) pero ni exclusiva ni excluyente de la doctrina establecida por la Sentencia del CJEU de 13 de mayo de 2014 (c-131/12, Caso Google v. Spain) ni impeditiva, en aras a la certeza y seguridad jurídica, de la consolidación legal en un Estado miembro de su doctrina jurisprudencial" ${ }^{32}$.

Para el cumplimiento de lo anteriormente señalado, desde la entrada en vigor del mencionado Reglamento, las empresas que operan dentro del mundo digital, deben tener una responsabilidad proactiva, tal como manifiesta el art. 5.2 del RGDP ${ }^{33}$. En palabras de Juan Carlos Bayo “... se exige una responsabilidad proactiva, en lugar de la responsabilidad reactiva (enfoque basado en riesgos), debiéndose actuar con carácter preventivo, tener la diligencia debida para evitar tratamientos o incumplimientos no deseados en la protección de los intereses de los ciudadanos en el ámbito de su privacidad" 34 .

Una de las principales manifestaciones de este principio es que la protección de los datos debe hacerse desde el diseño y por defecto. Esto para evitar las malas praxis que muchas veces llevan a cabo las empresas que operan en el mundo virtual, y que provocan un impacto en la intimidad y los datos personales de los ciudadanos.

Con esto se tratarán de evitar situaciones como las que llevaron a que la AEPD sancionara a algunas redes sociales, como por ejemplo a Facebook con multas superiores al millón de euros por falta de transparencia en sus políticas de privacidad.

32 Rallo (2019), pp. 38-39.

33 Art. 5.2 RGDP: "El responsable del tratamiento será responsable del cumplimiento de lo dispuesto en el apartado 1 y capaz de demostrarlo".

34 BAjO (2018), p. 281. 


\section{El olvido como constante preocupación de los Estados miembro de la Unión Europea}

Una preocupación y constante de todos los ordenamientos jurídicos nacionales de los países que forman parte de la Unión Europea ha sido el reconocimiento y protección de los derechos digitales de sus ciudadanos para adaptarse a las exigencias del derecho europeo, actualizando para ellos sus respectivas legislaciones nacionales.

\subsection{La Europa Continental y el olvido de sus ciudadanos}

A pesar de que Francia fue uno de los primeros países que tuvo un temprano desarrollo en la materia ${ }^{35}$, tal como ha quedado explicado hace algunas páginas, otro caso ejemplificante es el de Portugal, cuyo texto constitucional fue el primero en la historia europea en reconocer un precepto dedicado a la utilización de la información ${ }^{36}$.

Otro ejemplo es el alemán, que a pesar de no reconocer expresamente en su texto constitucional el derecho a la intimidad, ni a la protección de datos personales, ambos se fundamentan en una concepción más abierta en su artículo 2.1. que establece que "todos tienen derecho al libre desarrollo de su personalidad" ${ }^{37}$.

35 En Chile se incluyó la protección de datos personales, como derecho autónomo con reconocimiento constitucional en el año 2018, modificando el numeral 4 del artículo 19 de la CPR que dice: "La Constitución asegura a todas las personas el respeto y protección a la vida privada y a la honra de la persona y su familia, y asimismo, la protección de sus datos personales. El tratamiento y protección de estos datos se efectuará en la forma y condiciones que determine la ley".

36 Art. 35 Constitución Portugal de 1976: "1. Todos los ciudadanos tendrán derecho a tomar conocimiento de lo que conste en forma de registros mecanográficos acerca de ellos y de la finalidad a que se destinan las informaciones y podrán exigir la rectificación de los datos, así como su actualización. 2. No se podrá utilizar la informática para el tratamiento de datos referentes a convicciones políticas, fe religiosa o vida privada, salvo cuando se trate de la elaboración de datos no identificables para fines estadísticos. 3. Se prohíbe atribuir un número nacional únicos a los ciudadanos".

37 MuÑoz (2015), p. 218: "El artículo 2.1 de la Carta Fundamental alemana (Grundgesetz) prescribe que "toda persona tiene derecho al libre desarrollo de su personalidad siempre que no viole los derechos de otros ni atente contra el orden constitucional o la ley moral". La doctrina y la jurisprudencia alemana han concebido los derechos generales de la personalidad como un derecho fundamental comprendido en el derecho constitucional al libre desarrollo de la persona y la dignidad de esta. El Tribunal Constitucional alemán, por su parte, se ha pronunciado sobre la materia en el sentido de señalar que los derechos generales de la personalidad comprenden distintos modos de despliegue o manifestaciones de esta, a saber, la autodeterminación, el autorresguardo y la propia representación de la persona humana. La legislación alemana establece un espectro más amplio que el nuestro dentro del grupo de derechos de la personalidad, al menos, en su reconocimiento normativo. De esta forma, la protección del libre desarrollo de la personalidad se manifiesta 
En palabras de Pere Simón "el derecho a la autodeterminación informativa en Alemania fue creado jurisprudencialmente a través de la sentencia de 15 de diciembre de 1983 del Tribunal Constitucional alemán, que incorporaba una argumentación jurídica que sostuvo que el libre desarrollo de la personalidad y la dignidad humana -art. 2.1 y 1.1. respectivamente de la Constitución alemana- garantizan una esfera de vida personal y el libre desarrollo de sus condiciones fundamentales, a pesar de que estas no aparezcan recogidas de forma concluyente en garantías constitucionales concretas" ${ }^{38}$.

Este país tiene desde el 2017 una ley para la mejora del cumplimiento de la ley en redes sociales, que establece un límite temporal de 24 horas para que se retire contenido ilícito, y de 7 días para los restantes pudiendo llegar a imponer multas de hasta 50 millones de euros, en caso de que estos contenidos no se retiren del ámbito de las redes sociales.

A pesar de que una parte de la doctrina apunta a que esta cuestión pudiera estar relacionada con el tema de los delitos de odio ${ }^{39}$, en realidad también es una forma de recoger de forma especial el ámbito del derecho al olvido en las redes sociales, al igual que se ha hecho en España tras la entrada en vigor de la nueva ley de derechos digitales.

Por su parte, Reino Unido dictó en 1984 la Data Protection Act cuyo objetivo era establecer un régimen jurídico sobre la tenencia y el procesamiento automatizado de información. Esta ley consagró ya en los años 80 derechos de acceso, rectificación y borrado de datos personales, es decir, ya consagró un derecho al olvido.

Incluso se especula que esta y su sucesora, la Data Protection Act 1998, ayudaron a inspirar la Directiva 95/46, que es la antecesora del actual RGDP.

El país insular ha actualizado su legislación en esta materia a raíz de la entrada en vigor del Reglamento con la Data Protection Act 2018, en la que en palabras de Marina Sancho se "han incorporado derechos reconocidos en el Reglamento como el de acceso a los datos, a su traslado y a su borrado, incluyendo el derecho al olvido, así como incorporando prerrogativas nuevas como la facultad de solicitar el borrado automático de todo lo publicado en las redes sociales con

a través del resguardo de diversos subgrupos de derechos, que han sido desarrollados y dotados de contenido por la jurisprudencia”.

38 Simón (2015), p. 182.

39 Véase en este sentido López (2018). 
una edad menor a los 18 años (bautizado popularmente como el "derecho a la inocencia")" 40.

Y al igual que en otros países del continente, se creó un organismo para vigilar el cumplimiento de esta legislación, de la investigación en caso de infracción en materia de datos personales, el Information Commissioner Officer.

También es importante destacar la labor de Italia y su Garante per la Protezione dei Dati Personali, que ha desarrollado un código deontológico entre los que, a pesar de no haber una mención expresa al tema del derecho al olvido, se protege tanto la intimidad como los datos personales de las personas con las excepciones del interés público de la información.

En este punto de desarrollo en el reconocimiento y protección de los derechos digitales de los ciudadanos europeos, existe unanimidad respecto de la existencia del derecho al olvido digital, a pesar de que existen ciertas diferencias en algunos matices en función del país. España, Italia y Francia consideran que la solicitud debe hacerse al buscador. Grecia y Austria a la página web.

Esta última postura sí que podría poner en peligro el derecho a la información o incluso a la facultad de investigar, a pesar de que el Tribunal de Estrasburgo ${ }^{41}$ ha considerado que se puede exigir al medio de comunicación que publique una rectificación junto con el artículo original, en el que se advierta que el protagonista de esa información ha obtenido pronunciamientos judiciales favorables. Esto debido a que el órgano jurisdiccional del Consejo de Europa considera que las hemerotecas digitales cumplen funciones distintas de los medios de comunicación, y que, por lo tanto, deben tener la información actualizada, debido a la perpetuidad que esta va a tener en la Red. Es importante aclarar que esta obligación es solamente para noticias que posteriormente se han resuelto en procesos judiciales.

En este punto, tampoco hay unanimidad en el ámbito del Viejo Continente, ya que por ejemplo Alemania se ha mostrado en contra de que los medios de comunicación deban actualizar continuamente sus hemerotecas digitales, al contrario de Italia que sí mantiene esta postura ${ }^{42}$.

40 SANCHO (2019), p. 171.

41 STEDH de 16 de julio de 2013, caso Wergrzynowski y Smolczewski v. Polonia.

42 Simón (2015), p. 284: “... la doctrina jurisprudencial italiana sí ha reconocido un deber de diligencia y actualización de las noticias a los medios de comunicación. En concreto se ha señalado que, si bien no procede al borrado de la noticia que en su día fue publicada lícitamente, será responsabilidad del medio de comunicación reducir el grado de accesibilidad de la noticia impidiendo su indexación, cuando esta contenga 
Todo lo recientemente señalado demuestra cómo los países europeos están avanzando hacia una configuración compleja del derecho al olvido digital, en la que todavía quedan una gran cantidad de situaciones muy diversas que necesitan de solución.

\subsection{Especial referencia al caso español}

En este contexto europeo, en el que el derecho al olvido digital ha tenido un gran desarrollo en los últimos cinco años, es importante estudiar con más detenimiento el caso español, donde tras la publicación de la nueva Ley ${ }^{43}$ de Protección de Datos Personales y garantía de los derechos digitales publicada el 5 diciembre de 2018 se ha recogido un verdadero derecho al olvido distinguiendo entre el ámbito de los motores de búsqueda (art. 93 ${ }^{44}$ ) del de las redes sociales (art. 94 $4^{45}$ ).

datos inexactos o incompletos o por el mero paso del tiempo haya perdido su notoriedad e interés público, lesionando por ende los derechos de los afectados".

43 Ley Orgánica 3/2018, de 5 de diciembre, de Protección de Datos Personales y garantía de los derechos digitales.

44 Artículo 93 de la Ley Orgánica 3/2018, de 5 de diciembre, de Protección de Datos Personales y garantía de los derechos digitales. Derecho al olvido en búsquedas de Internet: "1. Toda persona tiene derecho a que los motores de búsqueda en Internet eliminen de las listas de resultados que se obtuvieran tras una búsqueda efectuada a partir de su nombre los enlaces publicados que contuvieran información relativa a esa persona cuando fuesen inadecuados, inexactos, no pertinentes, no actualizados o excesivos o hubieren devenido como tales por el transcurso del tiempo, teniendo en cuenta los fines para los que se recogieron o trataron, el tiempo transcurrido y la naturaleza e interés público de la información. Del mismo modo deberá procederse cuando las circunstancias personales que en su caso invocase el afectado evidenciasen la prevalencia de sus derechos sobre el mantenimiento de los enlaces por el servicio de búsqueda en Internet. Este derecho subsistirá aun cuando fuera lícita la conservación de la información publicada en el sitio web al que se dirigiera el enlace y no se procediese por la misma a su borrado previo o simultáneo. 2. El ejercicio del derecho al que se refiere este artículo no impedirá el acceso a la información publicada en el sitio web a través de la utilización de otros criterios de búsqueda distintos del nombre de quien ejerciera el derecho".

45 Artículo 94 de la Ley Orgánica 3/2018, de 5 de diciembre, de Protección de Datos Personales y garantía de los derechos digitales. Derecho al olvido en servicios de redes sociales y servicios equivalentes:"1. Toda persona tiene derecho a que sean suprimidos, a su simple solicitud, los datos personales que hubiese facilitado para su publicación por servicios de redes sociales y servicios de la sociedad de la información equivalentes. 2. Toda persona tiene derecho a que sean suprimidos los datos personales que le conciernan y que hubiesen sido facilitados por terceros para su publicación por los servicios de redes sociales y servicios de la sociedad de la información equivalentes cuando fuesen inadecuados, inexactos, no pertinentes, no actualizados o excesivos o hubieren devenido como tales por el transcurso del tiempo, teniendo en cuenta los fines para los que se recogieron o trataron, el tiempo transcurrido y la naturaleza e interés público de la información. Del mismo modo deberá procederse a la supresión de dichos datos cuando las circunstancias personales que en su caso invocase el afectado evidenciasen la prevalencia de sus derechos sobre el mantenimiento de los datos por el servicio. Se exceptúan de lo dispuesto en este apartado los datos que hubiesen sido facilitados por personas físicas en el ejercicio de actividades personales o domésticas. 3. En caso de que el derecho se ejercitase por un afectado respecto de datos que hubiesen sido facilitados al servicio, por él o por terceros, 
El primero de los casos considera que se va a reconocer el derecho al olvido cuando exista información sobre una persona, cuando su nombre se esté introduciendo en el buscador, siempre que dicha información sea inadecuada, inexacta, no pertinente, no actualizada o excesiva por el paso del tiempo, es decir, que ya no tenga interés público.

Pero además, en el siguiente artículo se contempla la posibilidad de que la información en el ámbito de las redes sociales desparezca por completo, es decir, no solamente que se desindexa sino que sea totalmente suprimida.

En palabras de Artemi Rallo "el derecho al olvido en redes sociales y servicios equivalentes de Internet supone una concreción del derecho de supresión amparada por el principio de calidad de los datos que resulta especialmente afectado por el transcurso del tiempo (exactitud, pertinencia, actualización) y que se instrumentaliza tanto por el derecho de supresión como de rectificación y por el derecho de oposición que atiende a las circunstancias personales que afectan al solicitante" 46 .

Además en el artículo $96^{47}$, relativo al derecho al testamento digital, se establece que no solo los herederos, sino otras personas vinculadas al fallecido puedan solicitar la supresión de contenidos y la eliminación de sus perfiles.

durante su minoría de edad, el prestador deberá proceder sin dilación a su supresión por su simple solicitud, sin necesidad de que concurran las circunstancias mencionadas en el apartado 2 ".

46 RALlo Lombarte (2019), pp. 40- 41.

47 Artículo 96 de la Ley Orgánica 3/2018, de 5 de diciembre, de Protección de Datos Personales y garantía de los derechos digitales. Derecho al olvido en búsquedas de Internet: Derecho al testamento digital."1. El acceso a contenidos gestionados por prestadores de servicios de la sociedad de la información sobre personas fallecidas se regirá por las siguientes reglas: a) Las personas vinculadas al fallecido por razones familiares o de hecho, así como sus herederos podrán dirigirse a los prestadores de servicios de la sociedad de la información al objeto de acceder a dichos contenidos e impartirles las instrucciones que estimen oportunas sobre su utilización, destino o supresión. Como excepción, las personas mencionadas no podrán acceder a los contenidos del causante, ni solicitar su modificación o eliminación, cuando la persona fallecida lo hubiese prohibido expresamente o así lo establezca una ley. Dicha prohibición no afectará al derecho de los herederos a acceder a los contenidos que pudiesen formar parte del caudal relicto. b) El albacea testamentario así como aquella persona o institución a la que el fallecido hubiese designado expresamente para ello también podrá solicitar, con arreglo a las instrucciones recibidas, el acceso a los contenidos con vistas a dar cumplimiento a tales instrucciones. c) En caso de personas fallecidas menores de edad, estas facultades podrán ejercerse también por sus representantes legales o, en el marco de sus competencias, por el Ministerio Fiscal, que podrá actuar de oficio o a instancia de cualquier persona física o jurídica interesada. d) En caso de fallecimiento de personas con discapacidad, estas facultades podrán ejercerse también, además de por quienes señala la letra anterior, por quienes hubiesen sido designados para el ejercicio de funciones de apoyo si tales facultades se entendieran comprendidas en las medidas de apoyo prestadas por el designado. 2. Las personas legitimadas en el apartado anterior podrán decidir acerca del mantenimiento o eliminación de los perfiles personales de personas fallecidas en redes sociales o servicios equivalentes, a menos que el fallecido hubiera decidido 
$\mathrm{Al}$ avance legislativo español en la materia, hay que sumar el jurisprudencial. En la STC 58/2018, de 4 de junio ${ }^{48}$, el debate giró en torno a quién tiene la responsabilidad de desindexar las noticias que están en las hemerotecas digitales: los buscadores o los medios de comunicación, partiendo de la premisa, tal como explica en el FJ5, "que el derecho al olvido es una vertiente del derecho a la protección de datos personales frente al uso de la informática (art. 18.1 CE), y es también un mecanismo de garantía para la preservación de los derechos a la intimidad y al honor, con los que está íntimamente relacionado, aunque se trate de un derecho autónomo".

El Tribunal Constitucional español consideró, en el primer pronunciamiento que ha tenido relativo al derecho al olvido digital, que, debido a que los protagonistas de la información no eran personas de relevancia pública debía prevalecer su derecho a la intimidad ${ }^{49}$, y que el diario de comunicación es responsable de resguardar estos derechos dentro de sus hemerotecas, desindexando de su buscador

acerca de esta circunstancia, en cuyo caso se estará a sus instrucciones. El responsable del servicio al que se le comunique, con arreglo al párrafo anterior, la solicitud de eliminación del perfil, deberá proceder sin dilación a la misma. 3. Mediante real decreto se establecerán los requisitos y condiciones para acreditar la validez y vigencia de los mandatos e instrucciones y, en su caso, el registro de los mismos, que podrá coincidir con el previsto en el artículo 3 de esta ley orgánica. 4. Lo establecido en este artículo en relación con las personas fallecidas en las comunidades autónomas con derecho civil, foral o especial, propio se regirá por lo establecido por estas dentro de su ámbito de aplicación".

48 Hechos de la sentencia: en los años 80 el diario "El País" publicó una noticia en su edición impresa respecto del desmantelamiento de una red de tráfico de estupefacientes, en donde estaba implicado un familiar de un alto cargo público, así como otros miembros de la clase alta. En ella se daba información de cómo había sido el paso por prisión de este grupo de personas, que además eran toxicómanas, por lo que durante su reclutamiento habían sufrido síndrome de abstinencia.

En el 2007 "El País" estableció acceso gratuito a su hemeroteca digital, momento a partir del cual al introducir el nombre y apellidos de estas personas en Google aparecía esta noticia como primer resultado.

Tal como establecen los antecedentes de la sentencia: "cuando D.F.C. y M.F.C. tomaron conocimiento de ello, ante la advertencia de un tercero, solicitaron de "El País" que cesara en el tratamiento de sus datos personales o, subsidiariamente, que sustituyera en la noticia digital sus nombres y apellidos por las iniciales de estos, adoptando, en todo caso, las medidas tecnológicas necesarias para que la página web, donde se había publicado la notica, no fuera indexada como resultado de la búsqueda en la red de información sobre las personas demandantes. El diario, basándose en su derecho fundamental a la libertad de información y en la imposibilidad de evitar la indexación de los buscadores, no accedió a la solicitud, propiciando la apertura de la vía judicial".

49 STC 58/2018, de 4 de junio, FJ2: “... las personas demandantes de amparo no tienen relevancia pública alguna, ni por sus profesiones, ni por su presencia en el espacio público, no por ninguna otra circunstancia, considera prevalente su derecho fundamental a la intimidad sobre la exigencia constitucional de publicidad de las resoluciones del Tribunal y, por tanto, entiendo justificada la exclusión de sus datos de la identidad en la Sentencia". 
interno la posibilidad de que al introducir los nombres y apellidos este se redirija directamente a la noticia en cuestión.

Además tuvo en cuenta el elemento temporal, es decir, el criterio que el mero transcurso del tiempo convierte una información en irrelevante ${ }^{50}$.

Es importante destacar que esta postura es contraria a la que manifestó el Tribunal Supremo español en el mismo caso (STS 545/2015 de 15 de octubre de 2015), y que estableció no se debía modificar la información en la hemeroteca, sino que esto es la responsabilidad del buscador, que es quien debe impedir que googleando el nombre y apellidos de los demandantes se llegue a la noticia. Y esto, porque el TS entiende que "las hemerotecas digitales gozan de la protección de la libertad de información, al satisfacer un interés público en el acceso a la información. Por ello, las noticias pasadas no pueden ser objeto de cancelación o alteración (...). Por tanto, la integridad de los archivos digitales es un bien jurídico protegido por la libertad de expresión que excluye las medidas que alteren su contenido eliminando o borrando datos contenidos en ellos, como puede ser la eliminación de los nombres de las personas que aparecen en tales informaciones o su sustitución por las iniciales".

Pero por su parte, el TC no está poniendo en cuestión que los nombres se deban desindexar de los motores de búsqueda, sino que da un paso más y lo que se plantea es que si la noticia debe estar indexada en la hemeroteca digital y que si se deben ocultar los nombres de las personas recurrentes de amparo u "oscurecerlos" a través del recurso al uso de sus iniciales (cuestión a la que se ha negado el TS y motivo por el cual la sentencia de casación ha sido recurrida en amparo). Y es que, tal como dice el FJ 6: "No estamos, por tanto, ante un nuevo conflicto con

50 STC 58/2018, de 4 de junio, FJ7: “Tal y como se viene afirmando, la relevancia pública de la información viene determinada tanto por la materia de la misma como por la condición de la persona a que se refiere. Pero el carácter noticiable también puede tener que ver con la "actualidad" de la noticia, es decir con su conexión, más o menos inmediata, con el tiempo presente. La materia u objeto de una noticia puede ser relevante en sentido abstracto, pero si se refiere a un hecho sucedido hace años, sin ninguna conexión con un hecho actual, puede haber perdido parte de su interés público o de su interés informativo para adquirir, o no, un interés histórico, estadístico o científico. No obstante su importancia indudable, ese tipo de intereses no guarda una relación directa con la formación de una opinión pública informada, libre y plural, sino con el desarrollo general de la cultura que, obviamente, actúa como sustrato de la construcción de las opiniones. Por esa razón podría ponerse en duda, en estos casos, la prevalencia del derecho a la información (art. 20.1 d) $\mathrm{CE}$ ) sobre el derecho a la intimidad de una persona (art. 18.1 CE) que, pasado un lapso de tiempo, opta por solicitar que estos datos e información, que pudieron tener relevancia pública en su día, sean olvidados. Por supuesto, cuando la noticia en cuestión ha sido digitalizada y se contiene en una hemeroteca, la afectación del derecho a la intimidad viene acompañada del menoscabo del derecho a la autodeterminación informativa (art. 18.4 CE)". 
los motores de búsqueda de los que han ocupado al Tribunal Supremo (por todas SSTS 191/2016, de 21 de julio, 1618/2016, de 4 de julio, 210/2016 de 16 de marzo), sino ante un conflicto circunscrito al uso de nombres propios como criterio de búsqueda y localización de noticias en el entorno de la hemeroteca digitalizada. En este contexto, los derechos que colisionan son, de un lado, el derecho a la supresión de datos de una base informatizada (art. 18.4 CE), en relación mediata e instrumental con la garantía del derecho al honor y la intimidad de las personas a las que conciernen los datos (art. 18.1 CE) y las libertades informativas ex artículo 20.1d) CE”.

Por ello, la sentencia estima parcialmente el recurso de amparo al pedirle al diario que desindexe de su motor de búsqueda los nombres de esas personas, para que cuando se introduzcan no la lleve a la noticia. No obstante, no estima pertinente que la noticia se tenga que anonimizar. Esto va en la línea de la sentencia del Caso Costeja.

En otro caso del año 2016, el Tribunal Supremo, en la STS 210/2016, de 5 de abril de $2016^{51}$, se pronunció en relación a un recurso de casación interpuesto por una persona que estaba solicitando a los buscadores que eliminasen la información relativa a un indulto que el poder ejecutivo le había concedido, y que ya el $\mathrm{BOE}^{52}$ había accedido a eliminar su nombre de su buscador interno, pero no a anonimizar, debido a que se trata de información pública.

Este caso, pone de relieve cómo la jurisprudencia española está manteniendo un adecuado equilibrio entre los derechos de la personalidad, que se pueden ver afectados en el entorno digital, y el derecho a la información, ya que aunque el BOE tomó ciertas medidas, no se produjo ni la anonimización de una infor-

51 Los hechos, tal como se explican en el FD 1: "El Boletín Oficial del Estado (en lo sucesivo, BOE) de 18 de septiembre de 1999 publicó el Real Decreto de 27 de agosto de 1999 por el que se indultó al demandante la pena privativa de libertad pendiente de cumplimiento, a la que había sido condenado en sentencia de la Sala Segunda del Tribunal Supremo de 18 de enero de 1990 . Esta sentencia resolvía el recurso de casación interpuesto contra otra de la Sección Quinta de la Audiencia Provincial de Madrid, de 26 de junio de 1986 , que le condenaba como autor de un delito contra la salud pública, por hechos cometidos en el año 1981 (...). Sin embargo, el organismo público decía que había adoptado las medidas a su alcance necesarias para evitar la automatización de los datos del demandante: había eliminado su nombre del buscador del BOE y actualmente no era posible acceder mediante su nombre, en ninguno de los buscadores de la web del BOE, al real decreto por el que se le indultó. Se añadía que, siguiendo indicaciones de la Agencia Española de Protección de Datos (en lo sucesivo, AEPD), los documentos en que aparecía el nombre del demandante habían sido incluidos en una lista de exclusión (robots.txt), para notificar a las empresas con buscadores en Internet que no debían utilizar esos datos, los cuales, en unos días, debían desaparecer de los buscadores de Internet".

52 Boletín Oficial del Estado. 
mación que es pública, y que debe seguir siendo accesible para los ciudadanos, ni se obligó a Google a que su buscador no siguiese estando linkeado con esta información.

Esto manifiesta, cómo se está haciendo una distinción entre las hemerotecas de los medios de comunicación y las fuentes públicas que contienen información pública.

Otra sentencia importante de señalar es la STS 12/2019, de 11 de enero de $2019^{53}$, relativa a información inexacta, en donde el diario además de no rectificar la información, no elimina la indexación del nombre de su protagonista.

En este caso la información aparecida en el medio de comunicación era errónea, por lo que el derecho al olvido debiese ir más allá de la mera desindexación de la información, ya que este tipo de informaciones no están amparadas por el derecho a la información. Por eso, la sentencia finalmente decide que Google debe desindexar esta información, porque a pesar de estar protagonizada por un personaje público, la información era inexacta ${ }^{54}$.

53 Hechos: "Así en la noticia publicada en el Diario EI País y en el blog, se hacía referencia a que los Agentes de medio Ambiente habían sorprendido a tres furtivos que eran trabajadores directos de la Administraron gallega, relatando seguidamente el enfrentamiento entre dichos "furtivos" y los agentes, que finalmente habían sido sancionados. También hace referencia a que los "presuntos furtivos" recibieron asimismo denuncia de Seprona que se desplazó al coto y que los guardias de Seprona indentificaron a los "furtivos" que reconocieron que estaban cazando jabalíes. Se hace constar que los tres fueron multados por haber estacionado el vehículo en medio de una pista forestal, incumpliendo la ley de Incendios en Galicia. Considera la Sala que los hechos así publicados no responden a la realidad, al menos al relato que se contiene en la sentencia de la Sala de lo Contencioso- Administrativo del Tribunal Superior de Justicia de Galicia, en la que se dice literalmente, que los agentes se habían reunido con diversos cazadores para "formar la cuadrilla previamente autorizada para ejercitar la caza en el terreno cinegético ordenado denominado PenaMaior, de cuyas resultas se producen unos incidentes por los cuales extienden aquéllos denuncias a tres de ellos por proferir amenazas ...."

54 STS 12/2019, de 11 de enero de 2019, FD 3: “... en este concreto supuesto debe prevalecer el derecho a la protección de datos personales del reclamante (que había ejercitado el derecho de cancelación de datos personales ante Google) frente a la libertad de información, teniendo en cuenta que la noticia que era objeto de difusión a través del buscador Google carecía de uno de los requisitos que deben concurrir para considerar legítimo el ejercicio de la libertad de información, cual es el de su veracidad, al ser inexactos los datos publicados (...). En efecto, consideramos que en el enjuiciamiento de este litigio que enfrenta a Google con la Agencia Española de Protección de Datos, el Tribunal de instancia ha realizado una adecuada ponderación de los derechos e intereses en conflicto, al amparar el derecho a la protección de los datos personales del Sr. Federico, cuya protección jurídica que había sido instada ante la Agencia Española de Protección de Datos, frente al derecho a la información sostenido por la mercantil Google LLC, responsable del motor de búsqueda de internet, pues, partiendo de la naturaleza y trascendencia pública de la información divulgada (que considera la sentencia impugnada de relevancia pública por concernir a hechos atribuidos a un funcionario público por la comisión de irregularidades cuando ejercitaba la actividad cinegética relacionadas con el desempeño de sus funciones públicas) así como el carácter sensible de la información para la vida privada de la 
Es un fallo un tanto llamativo, porque en ningún caso se establece cuál es la responsabilidad del medio de comunicación de mantener en su hemeroteca digital una información errónea, sin que proceda a la aclaración de la misma, a pesar de que el artículo 85 de la ley recientemente señalada establece que los medios digitales deben rectificar ${ }^{55}$ la información que tengan en línea y que sea errónea ${ }^{56}$.

En definitiva, tanto la legislación como la jurisprudencia española han contribuido a la positivización del derecho al olvido digital, así como a su complejización, dejando de ser ya solamente un derecho de supresión, para convertirse en uno de los derechos digitales cuyo reconocimiento y protección se ha convertido en imprescindible para el adecuado equilibrio entre el derecho a la información y los derechos de la personalidad de los usuarios en internet.

\section{Conclusiones}

El derecho al olvido digital se ha erigido en un derecho poliédrico cuyo reconocimiento y protección se revela como esencial para el normal desarrollo de la vida de los ciudadanos dentro del entorno digital.

Un derecho cuyos orígenes se remontan a los primeros avances tecnológicos y no a la creación de internet, que demuestra que esta necesidad de perdón y rendición es algo que los seres humanos llevan siglos reclamando, y que de forma pionera los tribunales estadounidenses y franceses ya comenzaron a reconocer desde que los medios impresos empezaron a tener una difusión masiva entre la sociedad.

persona afectada, llega a la convicción de que los hechos difundidos -objeto de la noticia- son parcialmente inexactos, tal como se desprende de la mencionada sentencia del Tribunal Superior de Justicia de Galicia, que descarta que hubiera practicado la caza de forma furtiva".

55 Rallo (2019), p. 43: "La técnica de los avisos aclaratorios en los medios de comunicación on line se ha ido progresivamente consolidando en la jurisprudencia europea dada su fácil viabilidad técnica para aportar mayor calidad al producto informativo y satisfacer las exigencias de actualización de contenidos".

56 Artículo 85 de la Ley Orgánica 3/2018, de 5 de diciembre, de Protección de Datos Personales y garantía de los derechos digitales. Derecho de rectificación en Internet: "1. Todos tienen derecho a la libertad de expresión en Internet. 2. Los responsables de redes sociales y servicios equivalentes adoptarán protocolos adecuados para posibilitar el ejercicio del derecho de rectificación ante los usuarios que difundan contenidos que atenten contra el derecho al honor, la intimidad personal y familiar en Internet y el derecho a comunicar o recibir libremente información veraz, atendiendo a los requisitos y procedimientos previstos en la Ley Orgánica 2/1984, de 26 de marzo, reguladora del derecho de rectificación. Cuando los medios de comunicación digitales deban atender la solicitud de rectificación formulada contra ellos deberán proceder a la publicación en sus archivos digitales de un aviso aclaratorio que ponga de manifiesto que la noticia original no refleja la situación actual del individuo. Dicho aviso deberá aparecer en lugar visible junto con la información original". 
Con la creación de la Web 2.o Europa se ha convertido en un ejemplo para el derecho al olvido digital, siendo el nuevo Reglamento de Protección de Datos de la UE la primera ley internacional que lo ha positivizado, a pesar de que debido a la redacción del artículo 17 lo ha limitado a ser un derecho de supresión.

Debate que se puso sobre la mesa en el Viejo Continente a raíz de la cuestión prejudicial que España elevó al Tribunal de Luxemburgo, y que produjo que con la sentencia del Caso Costeja del año 2014 se estableciese un punto de inflexión respecto de la relación de los buscadores con las legislaciones nacionales, al establecer que estos sí son responsables por el tratamiento de los datos, y que por lo tanto, deben atenerse a las resoluciones dictadas por las diferentes Agencias de Protección de Datos europeas, así como a los requerimientos que les hacen los tribunales nacionales de los Estados miembro de la UE.

Esto no fue sino el principio del derecho al olvido digital, ya que tal como ha quedado comprobado, los países europeos comenzaron a adaptar sus legislaciones internas, estableciendo de forma muy acertada un mayor alcance para el derecho al olvido digital, más allá del derecho de supresión, y comenzando a establecer supuestos diferenciados en función del soporte en el que se encontraba la información que se deseaba eliminar, diferenciando entre la desindexación para el caso de los motores de búsqueda, al estilo del Caso Costeja, de la supresión total de información personal en el ámbito de las redes sociales. La jurisprudencia también está ayudando a su delimitación, al establecer la responsabilidad que tienen los buscadores internos tanto de los medios de comunicación, como de las fuentes oficiales de información, y logrando un equilibrio entre información y derechos de la personalidad.

En definitiva, olvidar en el Viejo Continente ya es posible sin afectar el derecho a la información. Europa se ha convertido en la firme defensora del derecho al olvido digital y en un ejemplo para los ordenamientos jurídicos de otros países.

\section{Bibliografía citada}

Adsuara, Borja (2019): "Derechos de rectificación, supresión (olvido) y portabilidad (de los datos) y de limitación y oposición (al tratamiento)”, en RALLO Lombarte, Artemi (dir.), Tratado de protección de datos. Actualizado con la Ley Orgánica 3/2018, de 5 de diciembre, de protección de datos personales y garantía de los derechos digitales (Valencia, Tirant lo Blanch), pp. 313-352. 
Adsuara, Borja (2018): “El ciudadano frente al reglamento", en López Calvo, José (coord.), El nuevo marco regulatorio derivado del Reglamento Europeo de Protección de Datos (Madrid, Wolters Kluwer), pp. 163- 172.

Álvarez Caro, María (2015): Derecho al olvido en internet: el nuevo paradigma de la privacidad en la era digital (Madrid, Reus).

Anguita Ramírez, Pedro (2016): Acciones de protección contra Google. Análisis del llamado derecho al olvido en buscadores, redes sociales y medios de comunicación (Santiago de Chile, Librotecnia).

Aparicio Salom, Javier (2018): “Derechos del interesado (Arts. 12-19)”, en López Calvo, José (coord.), El nuevo marco regulatorio derivado del Reglamento Europeo de Protección de Datos (Madrid, Wolters Kluwer), pp. 363- 400.

BAJO, Juan Carlos (2018): "Consideraciones sobre el principio de responsabilidad proactiva y diligencia (accountability). Experiencias desde el compliance”, en López Calvo, José (coord.), El nuevo marco regulatorio derivado del Reglamento Europeo de Protección de Datos (Madrid, Wolters Kluwer), pp. 278-288.

Berrocal Lanzarot, Isabel (2017): Derecho de supresión de datos o derecho al olvido (Madrid, Reus).

Совасно López, Ángel (2019): “Reflexiones en torno a la última actualización del derecho al olvido digital”, en Revista de Derecho Político ( No $^{\circ}$ 104, enero-abril), pp. 197- 227.

Cotino Hueso, Lorenzo (2015): "El conflicto entre las libertades de expresión e información en internet y el derecho a la protección de datos. El derecho al olvido y sus retos: "un falso derecho, a juzgar por un falso tribunal'", en BELL Mallén, Ignacio y Corredoira y Alfonso, Loreto (dirs.), Derecho de la información. El ejercicio del derecho a la información y su jurisprudencia (Madrid, Centro de Estudios Políticos y Constitucionales), pp. 387- 410.

Covarrubias Cuevas, Ignacio (2013): La vida privada de las figuras públicas. El interés público como argumento que legitima la intromisión en la vida privada (Santiago de Chile, Thomson Reuters).

De Terwagne, Cecile (2012): "Privacidad en Internet y el derecho a ser olvido/ al olvido", en Revista de Internet, Derecho y Política (No 13, febrero), pp. 53-66.

Herrera Carpintero, Paloma (2016): "El derecho a la vida privada y las redes sociales en Chile", en Revista Chilena de Derecho y Tecnología (Vol. 5, № 1), pp. 87- 112. 
Llaneza, Paloma (2018): "La adaptación de los consentimientos tácitos y presuntos: el uso del interés legítimo”, en López Calvo, José (coord.), El nuevo marco regulatorio derivado del Reglamento Europeo de Protección de Datos (Madrid, Wolters Kluwer), pp. 717- 734.

López Calvo, José (2018): "Un reglamento poliédrico que necesita un acercamiento poliédrico”, en López CALvo, José (coord.), El nuevo marco regulatorio derivado del Reglamento Europeo de Protección de Datos (Madrid, Wolters Kluwer), pp. 81- 94.

Moreno Bobadilla, Ángela (2019): "El derecho al olvido digital: una brecha entre Europa y Estados Unidos", en Revista de Comunicación Universidad de Piura (Vol. 18, No 1), pp. 259- 276.

Moreno Bobadilla, Ángela (2017): Intimidad y menores (Madrid, Centro de Estudios Políticos y Constitucionales).

Moreno Bobadilla, Ángela y Serrano Maíllo (2017): "El derecho al olvido digital. Especial consideración al caso chileno", en Machado Martins, Priscila (coord.), Pensamiento Jurídico Central (Valencia, Tirant lo Blanch), pp. 37-52.

Muñoz Massouh, Ana María (2015): "Eliminación de datos personales en internet: El reconocimiento del derecho al olvido", en Revista Chilena de Derecho y Tecnología (Vol. 4, No 2), pp. 215- 261.

Nogueira Alcalá, Humberto (2002): El derecho a la libertad de opinión e información y sus límites (Honra y vida privada) (Santiago de Chile, Legal Publishing).

Orza Linares, Ramón M. (2018): "La regulación del "derecho al olvido" en la Unión Europea. Aspectos críticos”, en Durán Ruiz, Francisco (dir.), Desafíos de la protección de los menores en la sociedad digital. Internet, redes sociales y comunicación (Valencia, Tirant lo Blanch), pp.125-161.

Pérez Goméz, Ana María (2016): “Cuando Google juega con la información privada... el derecho al olvido digital en Europa, una lucha de titanes”, en Revista La Propiedad Inmaterial (julio-diciembre), pp. 173- 186.

Piñar Mañas, José Luis y Recio Gayo, Miguel (2019): El derecho a la protección de datos en la jurisprudencia del Tribunal de Justicia de la Unión Europea (Madrid, Wolters Kluwer).

Rallo Lombarte, Artemi (2019): "Del derecho a la protección de datos a la garantía de nuevos derechos digitales", en Rallo Lombarte, Artemi (dir.), Tratado de protección de datos. Actualizado con la Ley Orgánica 3/2018, de 5 de 
diciembre, de protección de datos personales y garantía de los derechos digitales (Valencia, Tirant lo Blanch), pp. 23-52.

Rallo Lombarte, Artemi (2017): "De la "libertad informática" a la constitucionalización de nuevos derechos digitales (1978- 2018)", en Revista de Derecho Político ( $\mathrm{N}^{\circ}$ 100, septiembre-diciembre), pp. 639- 669.

Rallo Lombarte, Artemi (2014): El derecho al olvido en internet. Google versus España (Madrid, Centro de Estudios Políticos y Constitucionales).

Rebollo Delgado, Lucrecio (2018): Protección de datos en Europa. Origen, evolución y regulación actual (Madrid, Dykinson).

Reusser Monsálvez, Carlos (2018): Derecho al olvido. La protección de datos personales como límite a las libertades informativas (Santiago de Chile, Der Ediciones).

SAnCho López, Marina (2019): La protección de datos en el Reino Unido: evolución del right to privacy y escenarios post brexit (Navarra, Thomson Reuters Aranzadi).

Simón Castellano, Pere (2015): El reconocimiento del derecho al olvido digital en España y en la UE (Barcelona, Bosch).

Simón Castellano, Pere (2012): El régimen constitucional del derecho al olvido digital (Valencia, Tirant lo Blanch).

Touriño, Alejandro (2014): El derecho al olvido y a la intimidad en Internet (Madrid, Catarata).

\section{Jurisprudencia citada}

Tribunal Europeo de Derechos Humanos:

STEDH de 16 de julio de 2013, caso Wergrzynowski y Smolczewski v. Polonia.

Tribunal de Justicia de la Unión Europea:

Caso Digital Rights Ireland y Seitlinger y otros, asunto C-293-12.

Caso Costeja, asunto C- 131/12.

Caso Fashion ID GmbH \& Co. KG contra Verbraucerzentrale NRW eV, asunto C-40/17.

Estados Unidos:

Corte Suprema, caso Briscoe v. Reader's Digest Assoc. de 1971.

Corte Suprema, caso Time Inc. v. Hill de 1967.

Corte de Apelaciones de California, caso Melvin v. Reid en 1931.

Francia: 
Caso Mme. M. c. Filipacchi et Cogedipresse de 1983.

Tribunal de Gran Instancia de Sena, del 4 de octubre de 1965.

España:

STC 58/2018, de 4 de junio de 2018.

STS 12/2019, de 11 de enero de 2019.

STS 210/2016, de 5 de abril de 2016.

STS 545/2015, de 15 de octubre de 2015.

\section{Normas jurídicas citadas}

\section{Unión Europea:}

Reglamento (UE) 2016/679 del Parlamento Europeo y del Consejo, de 27 de abril de 2016, relativo a la protección de las personas físicas en lo que respecta al tratamiento de datos personales y a la libre circulación de estos.

Francia:

Ley 78 -17, de 6 de enero de 1978, que regulaba la libertad del tratamiento de informaciones personales, disponiendo el principio del derecho al olvido digital. España:

Ley Orgánica 3/2018, de 5 de diciembre, de Protección de Datos Personales y garantía de los derechos digitales.

Reino Unido:

Data Protection Act, de 2018.

Data Protection Act, de 1998.

Data Protection Act, de 1984. 